\title{
Ocorrência e caracterização da tuberculose em caprinos leiteiros criados no estado de Pernambuco ${ }^{1}$
}

INDEX TERMS: Tuberculosis, clinics, diagnosis, goats, Mycobacterium bovis.

RESUMO-- Acreditou-se durante muito tempo que a espécie caprina era resistente à infecção por Mycobacterium bovis, porém tal hipótese foi desconsiderada quando relatos da enfermidade surgiram em vários países. No entanto, ainda permanecem desconhecidas certas características da tuberculose em caprinos e suas implicações na saúde pública e caprinocultura nacional. Objetivou-se com este trabalho descrever os aspectos nosológicos, radiológicos, anátomo-histopatológicos, baciloscópicos e biomoleculares da tuberculose em caprinos leiteiros com doença respiratória, naturalmente infectados e procedentes do estado de Pernambuco. Para isso foram tuberculinizadas 442 cabras com sintomas respiratórios e, destas, 3,4\% (15/442) foram consideradas positivas ao teste. Dos animais positivos, sete foram monitorados clinicamente durante 12 meses, descrevendo-se os achados obtidos. 0 agente etiológico

\footnotetext{
${ }^{1}$ Recebido em 9 de janeiro de 2012.

Aceito para publicação em 25 de abril de 2012.

${ }^{2}$ Departamento de Medicina Veterinária, Universidade Federal Rural de Pernambuco (UFRPE), Av. Dom Manuel de Medeiros s/n, Recife, PE 52171-900, Brasil. *Autor para correspondência: lucio@dmv.ufrpe.br

${ }^{3}$ Centro Nacional de Pesquisa de Gado de Corte (CNPGC), Empresa Brasileira de Pesquisa Agropecuária (Embrapa), BR 262 Km 4, Cx. Postal 154, Campo Grande, MS 79002-970, Brasil.
}

foi identificado através da reação em cadeia da polimerase, por amplificação de sequências genômicas do Complexo Mycobacterium tuberculosis e posteriormente de Mycobacterium bovis. Este é o primeiro diagnóstico molecular com caracterização do envolvimento do Mycobacterium bovis na tuberculose caprina no Brasil.

TERMOS DE INDEXAÇÃO: Tuberculose, clínica, diagnóstico, cabras, Mycobacterium bovis.

\section{INTRODUÇÃO}

O complexo Mycobacterium tuberculosis é formado pelas espécies M. tuberculosis e M. bovis, e por espécies descritas mais recentemente, como M. caprae (Aranaz et al. 2003) e M. pinnipedii (Cousins et al. 2003), isoladas de caprinos e leão marinho, respectivamente.

Postulou-se por muito tempo que a espécie caprina era naturalmente resistente à infecção pelo M. bovis (Murray, McNutt \& Purwin 1921, Gutiérrez et al. 1995). Todavia tal hipótese foi questionada após o registro da doença em caprinos em alguns países (Milne 1955, Reynoso et al. 1999). Sua gênese encontra-se estreitamente relacionada à proximidade com rebanhos bovinos infectados (Reynoso et al. 1999, Pugh 2004) e a prática disseminada entre caprinocultores em realizar o aleitamento de cabritos com leite de 
vacas, como medida profilática ao vírus da artrite encefalite caprina (Melo et al. 2005a).

No Brasil, a tuberculose caprina e seu papel na gênese da tuberculose zoonótica são ainda desconhecidos, admitindo-se inclusive que não existam dados que justifiquem a implantação de medidas específicas visando o controle sistemático da doença em pequenos ruminantes (Brasil 2006). Contudo, admite-se sua transmissibilidade para humanos (Golden 1921) e reconhece-se a coexistência da doença com a tuberculose humana e bovina (Melo et al. 2005a, Brasil 2006), em meio à existência de um mercado informal de leite (Associação Brasileira de Buiatria 1998) e ao hábito cultural da população de algumas regiões do país em ainda consumir este leite in natura.

No Estado de Pernambuco, estudos vêm sendo realizados desde o ano de 2005 com o objetivo de elucidar a etiopatogenia de síndromes respiratórias que ocorrem em caprinos leiteiros. Dentre eles destaque especial foi a identificação de 7,7\% (13/168) dos caprinos reagentes ao teste tuberculínico (Melo et al. 2005a,b, Melo et al. 2008), adaptado para a espécie (Silva et al. 2006).

Este estudo foi realizado com o objetivo de descrever os aspectos nosológicos, radiológicos, anátomo-histopatológicos e biomoleculares da tuberculose em caprinos leiteiros com doença respiratória, naturalmente infectados e procedentes da Mesorregião Metropolitana do Recife e Sertão de Pernambuco.

\section{MATERIAL E MÉTODOS}

A amostragem foi estabelecida por conveniência, com base em estudo não probabilístico (Marotti et al. 2008), sendo considerados 442 caprinos, provenientes de 15 rebanhos, compostos pelas raças Saanen, Toggenburg e Parda Alpina, com idade média entre dois a sete anos, e que apresentavam síndrome clínico-respiratória e, segundo os proprietários, diminuição na produção de leite. Os animais foram submetidos ao exame clínico e ao teste da tuberculina, pela técnica cervical comparativa (TCC), utilizando-se derivados de proteína purificada da estirpe D4 do M. avium (PPDa)2 e da estirpe AN5 de Mycobacterium bovis (PPDb) .

Dos animais reagentes ao TCC, tomando-se como referência os ensaios do teste padronizado experimentalmente para caprinos (Silva et al. 2006), uma amostragem foi selecionada por conveniência para monitoramento durante dois anos no Hospital Veterinário da Universidade Federal Rural de Pernambuco. Neste período, foram usadas semiotécnicas e procedimentos anátomo-patológicos com vista ao diagnóstico, inclusive necropsia nos animais que foram ao óbito ou eutanasiados (AVMA 2001), com base em metodologias clássicas (Jones, Hunt \& King 1997, Pugh
2004, Quinn et al. 2005, Radostits et al. 2007), o que possibilitou a descrição dos aspectos nosológicos, radiológicos, baciloscópicos e anátomo-histopatológicos. Adicionalmente, foram realizados dois retestes com intervalo de 60 dias.

Os ensaios biomoleculares utilizando a reação em cadeia da polimerase (PCR) do tipo Nested em tempo real (Miyazaki et al. 1993) foram conduzidos no Laboratório de Imunoepidemiologia do Centro de Pesquisas Aggeu Magalhães (CPqAM, Fiocruz), estado de Pernambuco, e na Empresa Brasileira de Pesquisa Agropecuária (Embrapa), estado do Mato Grosso do Sul, empregando-se kit comercial para a extração de DNA e para as reações de amplificação , seguindo recomendações dos respectivos fabricantes.

A sequência de primers, os genes alvo e o comprimento do fragmento amplificado para os genes RV2807 (Complexo M. tuberculosis), MMSP6 (M. bovis), RV3343 (M. tuberculosis) e CD (Complexo M. avium), utilizados e considerados neste estudo, foram anteriormente publicados (Araújo et al. 2011) e estão descritas no Quadro 1. Como controle positivo, foram utilizadas amostras de cultura dos respectivos microorganismos. Para o controle negativo, o DNA foi excluído da reação.

As amostras biológicas testadas foram derivadas de quatro dos animais monitorados, sendo quatro espécimes de sangue total com anticoagulante, um de leite, um de linfonodo mesentérico, um de fígado, três de pulmão e um de conteúdo de abscesso em cavidade abdominal, colhidas a campo ou durante a necropsia mediante a identificação das lesões granulomatosas e/ ou abscedantes.

\section{RESULTADOS}

Dos caprinos examinados, 3,4\% (15/442) reagiram ao TCC (Fig.1-3). Dos 15 positivos, sete foram selecionados para serem acompanhados no Hospital Veterinário da Universidade Federal Rural de Pernambuco. Os sete caprinos apresentaram intensidades das reações imunoalérgicas, em valores médios ( \pm desvio padrão), de $11,8( \pm 4,0)$ e $5,9( \pm 3,5)$ $\mathrm{mm}$ ao PPDb e PPDa, respectivamente. A diferença média entre as duas (PPDb e PPDa) foi de 5,9 $( \pm 2,2) \mathrm{mm}$ (Quadro 2). Em relação aos retestes, dois animais não reagiram ao último realizado.

A frequência dos achados nosológicos, radiológicos, anátomo-histopatológicos e biomoleculares da tuberculose nos caprinos monitorados encontra-se descrita no Quadro 3.

Ao exame físico, foi observado que todos os animais $(100 \%, 7 / 7)$ apresentaram emaciação, anemia, hipertrofia de linfonodos e secreção nasal bilateral. Em 71\% (5/7) destes animais identificou-se uma síndrome respiratória

\footnotetext{
${ }^{4}$ Purified Protein Derivated, Tecpar Inc., Curitiba, PR.

${ }^{5}$ DNeasy Blood \& Tissue, Qiagen, Valencia, CA.

${ }^{6}$ TaqMan Master Mix, Applied Biosystems Inc., Carlsbad, CA.
}

Quadro 1. Genes alvo, sequência de primers e comprimento do fragmento amplificado para o Complexo M. tuberculosis, Complexo M. avium, M. bovis e M. tuberculosis

\begin{tabular}{|c|c|c|c|}
\hline & Gene alvo & Sequência de primers 5' a 3' & Fragmento (pares de base) \\
\hline Complexo M. tuberculosis & RV2807 & $\mathrm{D}^{\mathrm{a}}$ - GGC GGT GGC GGA GTT GAA GGC GAT G & 443 \\
\hline & & $\mathrm{R}^{\mathrm{b}}$ - GCC GCG AGC GAG TCT GGG CGA TGT C & \\
\hline Complexo M. avium & CD & $\begin{array}{c}\mathrm{D}^{\mathrm{a}}-\text { GCC GCC GCG CCG CAT CT } \\
\mathrm{R}^{\mathrm{b}}-\text { TCG TCG GAG GCC AGG AAC AGC }\end{array}$ & 368 \\
\hline M. bovis & MMSP6 & $\begin{array}{l}\mathrm{D}^{\mathrm{a}} \text { - GTG GCG GTC GCG GGA TTC AGC GTC T } \\
\mathrm{R}^{\mathrm{b}} \text { - TTA TGG CGG CCA CAC CCA CCC AAA AC }\end{array}$ & 474 \\
\hline M. tuberculosis & RV3343 & $\begin{array}{l}\mathrm{D}^{\mathrm{a}} \text { - TCG GTA TCG GGC TCA GCG GGG ACA A } \\
\mathrm{R}^{\mathrm{b}} \text { - GCG GGC CGT AGT GGT CGA TCG TGA T }\end{array}$ & 525 \\
\hline
\end{tabular}




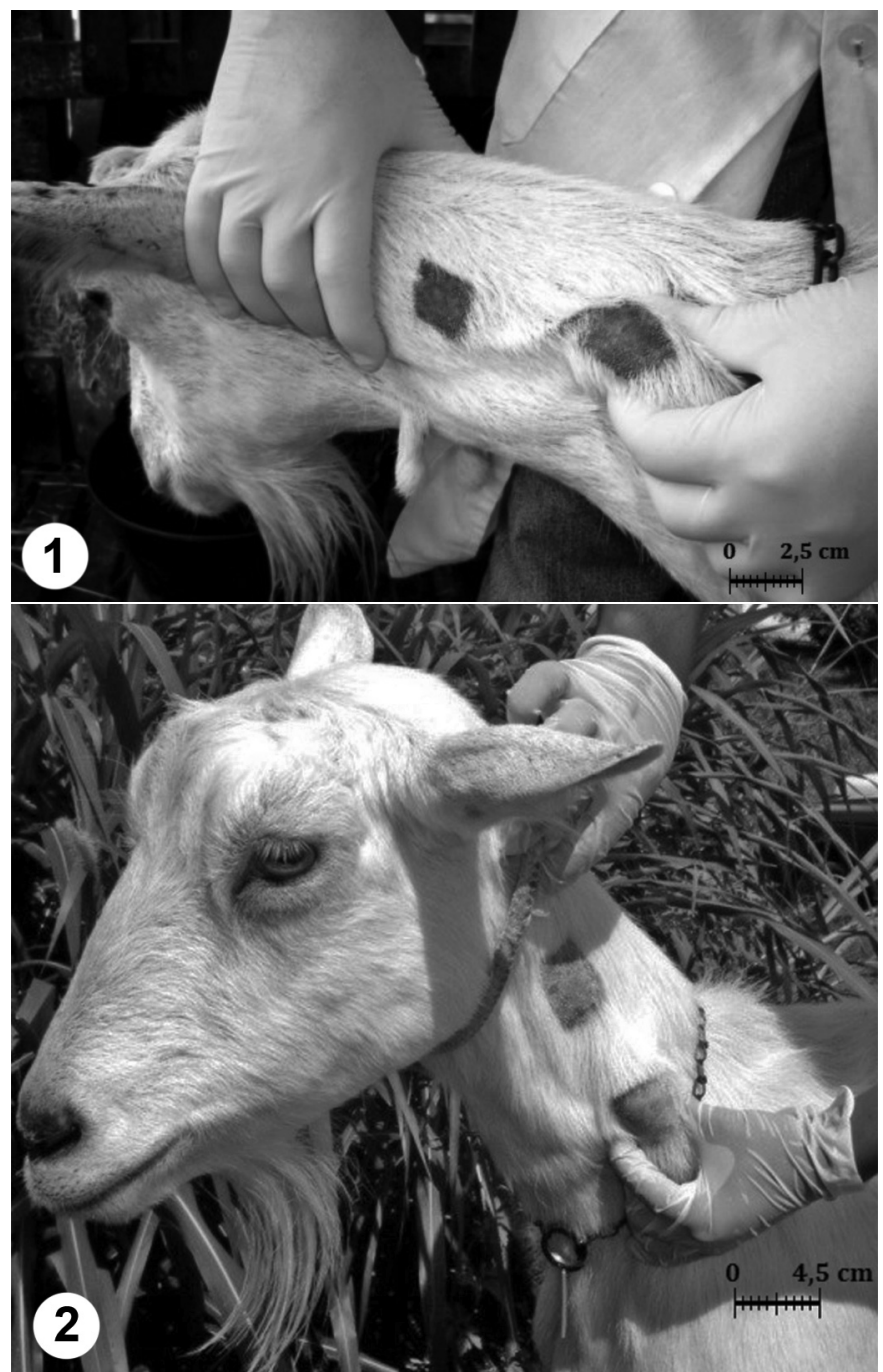

Fig.1-2. Palpação das reações imunoalérgicas em caprinos reagentes ao teste da tuberculina, com destaque para a magnitude expressiva da reação à PPD bovina.

caracterizada por respiração abdominal (43\%, 3/7), tosse $(57 \%, 4 / 7)$, áreas de silêncio pulmonar alternadas com crepitações e sibilos $(29 \%, 2 / 7)$, além de abscessos localizados no vestíbulo bucal $(14 \%, 1 / 7)$. Avaliações clínicas que precederam o período de monitoramento demonstra-

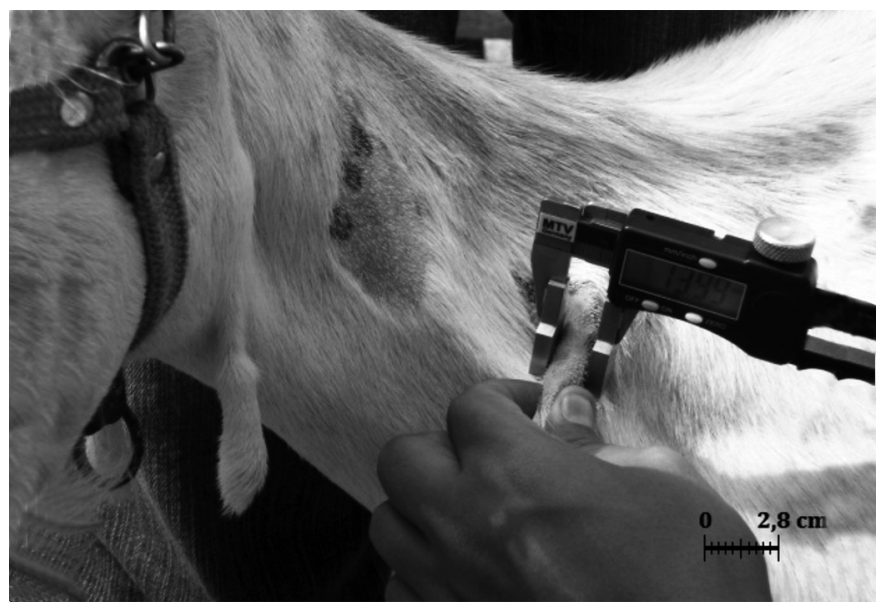

Fig.3. Cutimetria em caprino regente ao teste da tuberculina, com destaque para a magnitude de 13,99 $\mathrm{mm}$ da reação à PPD bovina.

ram as alterações nosológicas acima citadas, cuja evolução ocorreu de forma gradual, resultando no óbito de três caprinos em decorrência de colapso cardiorrespiratório $(43 \%, 3 / 7)$ ou na necessidade de eutanásia de quatro deles devido ao avançado estado de caquexia (57\%, 4/7).

Nas imagens radiográficas latero-lateral do tórax (Fig.4) de $86 \%(6 / 7)$ das cabras, foi observada opacidade de ambos os campos pulmonares, com a presença de nódulos radiopacos circunscritos de tamanhos variando desde grandes granulomas $(29 \%, 2 / 7)$, que comprometiam o lobo diafragmático, até pequenos $(57 \%, 4 / 7)$, característicos de tuberculose miliar. Além disso, o exame radiográfico da glândula mamária de um caprino $(14 \%$ - 1/7) revelou nódulos radiopacos.

$\mathrm{Na}$ necropsia, os achados anatomopatológicos foram caracterizados principalmente por lesões pulmonares $(71 \%, 5 / 7)$ (Fig.5-7), focais $(29 \%, 2 / 7)$ ou difusas $(43 \%$, 3/7). Macroscopicamente, foi observada consolidação do parênquima pulmonar, com a presença de lesões nodulares salientes e difusas, de tamanho variado e coloração amarelada. Ao corte, as lesões apresentavam consistência e aspecto friável, com endurecimento num plano mais profundo, coincidindo com áreas de calcificação e de consistência arenosa ou pétrea. Observaram-se alterações hepáticas em

Quadro 2. Intensidade das reações imunoalérgicas dos caprinos positivos ${ }^{\mathrm{a}}$ ao teste da tuberculina

\begin{tabular}{|c|c|c|c|c|c|c|c|}
\hline \multirow[t]{2}{*}{ Caprinos } & \multicolumn{3}{|c|}{$\mathrm{PPDa}^{\mathrm{b}}$} & \multicolumn{3}{|c|}{$\mathrm{PPDb}^{\mathrm{c}}$} & \multirow[t]{2}{*}{$\Delta \mathrm{B}-\Delta \mathrm{A}$} \\
\hline & $A 0^{d}$ & $\mathrm{~A} 72^{\mathrm{e}}$ & $\Delta \mathrm{A}(\mathrm{A} 72-\mathrm{A} 0)$ & $B 0^{f}$ & B72g & $\Delta \mathrm{B}(\mathrm{B} 72-\mathrm{B} 0)$ & \\
\hline 1 & 4,0 & 7,0 & 3,0 & 4,0 & 12,0 & 8,0 & 5,0 \\
\hline 2 & 3,5 & 9,7 & 6,2 & 3,2 & 12,8 & 9,6 & 3,4 \\
\hline 3 & 3,8 & 11,8 & 8,0 & 3,5 & 18,6 & 15,1 & 7,1 \\
\hline 4 & 3,8 & 15,2 & 11,4 & 4,0 & 23,1 & 19,1 & 7,7 \\
\hline 5 & 3,8 & 11,8 & 8,0 & 3,2 & 13,9 & 10,7 & 2,7 \\
\hline 6 & 4,2 & 5,6 & 1,4 & 3,0 & 11,9 & 8,9 & 7,5 \\
\hline 7 & 3,7 & 6,79 & 3,13 & 3,1 & 13,99 & 10,89 & 7,76 \\
\hline $\begin{array}{c}\text { Média } \\
\text { (desvio padrão) }\end{array}$ & $\begin{array}{c}3,8 \\
( \pm 0,2)\end{array}$ & $\begin{array}{c}9,7 \\
( \pm 3,5)\end{array}$ & $\begin{array}{c}5,9 \\
\pm( \pm 3,5)\end{array}$ & $\begin{array}{c}3,4 \\
( \pm 0,4)\end{array}$ & $\begin{array}{c}15,2 \\
( \pm 4,2)\end{array}$ & $\begin{array}{c}11,8 \\
( \pm 4,0)\end{array}$ & $\begin{array}{c}5,9 \\
( \pm 2,2)\end{array}$ \\
\hline
\end{tabular}

a Foi considerado positivo animais que apresentaram $\Delta \mathrm{B}-\Delta \mathrm{A}$ maior ou igual a $2,5 \mathrm{~mm}$ (Silva et al. 2006), b derivados de proteína purificada da estirpe D4 do M. avium, ${ }^{\mathrm{c}}$ derivados de proteína purificada da estirpe AN5 do Mycobacterium bovis, ${ }^{\text {d }}$ cutimetria $(\mathrm{mm})$ precedente à inoculação da PPDa, ${ }^{\mathrm{e}}$ cutimetria $(\mathrm{mm})$ após 72 horas da inoculação da PPDa, cutimetria $(\mathrm{mm})$ precedente à inoculação da PPDb, ${ }^{\mathrm{g}}$ cutimetria $(\mathrm{mm})$ após 72 horas da inoculação da PPDb. 
Quadro 3. Frequência de achados clínico-patológicos e exames complementares relacionados à tuberculose em caprinos criados no estado de Pernambuco

\begin{tabular}{|c|c|c|c|c|c|}
\hline Caprinos & $\begin{array}{c}\text { Achados } \\
\text { nosológicos }\end{array}$ & $\begin{array}{c}\text { Achados } \\
\text { radiográficos }\end{array}$ & $\begin{array}{l}\text { Achados anátomo- } \\
\text { histopatológicos }\end{array}$ & Baciloscopia & $\begin{array}{l}\text { PCR - Complexo Myco- } \\
\text { bacterium tuberculosis }\end{array}$ \\
\hline 1 & Presentes & Presentes & Presentes & Negativa & Não realizada \\
\hline 2 & Presentes & Presentes & Presentes & Negativa & Positiva $^{a}$ \\
\hline 3 & Presentes & Presentes & Ausentes & Negativa & Não realizada \\
\hline 4 & Presentes & Presentes & Ausentes & Positiva & Positiva $^{b}$ \\
\hline 5 & Presentes & Presentes & Presentes & Positiva & Positiva $^{b}$ \\
\hline 6 & Presentes & Presentes & Presentes & Não realizada & Não realizada \\
\hline 7 & Presentes & Presentes & Presentes & Positiva & Positiva $^{b}$ \\
\hline Frequência & $100 \%(7 / 7)$ & $100 \%(7 / 7)$ & $71,4 \%(5 / 7)$ & $50 \%(3 / 6)$ & $100 \%(4 / 4)$ \\
\hline
\end{tabular}

a Pesquisa para o complexo Mycobacterium tuberculosis, processada no CPqAM/ PE, ${ }^{\text {b }}$ pesquisa para M. bovis, processada na Embrapa CNPGC, Campo Grande, MS.

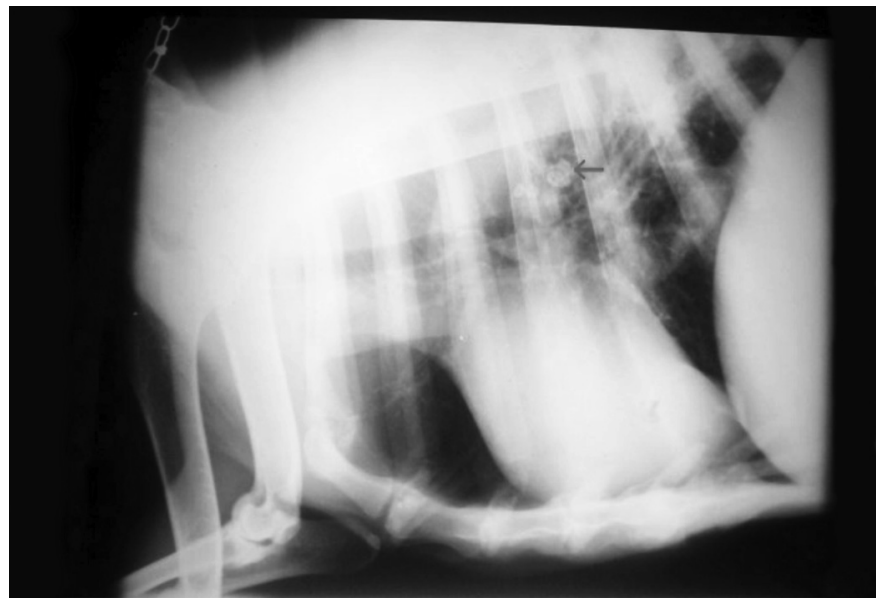

Fig.4. Radiografia latero-lateral torácica de caprino demonstrando nódulos radiopacos em campos pulmonares (seta).

$29 \%(2 / 7)$ das cabras necropsiadas, caracterizadas por lesões de tamanho que variavam de pequenos pontos até 2,5 cm de diâmetro, de consistência caseosa e coloração amarelada. Dentre os animais com lesões hepáticas, um apresentou lesões pulmonares de forma associada.

Os achados histopatológicos encontrados nos fragmentos de pulmão de dois animais necropsiados incluíam áreas de necrose de caseificação tirar com calcificação distrófica no centro (Fig.8), circundadas por cápsulas conjuntivas no

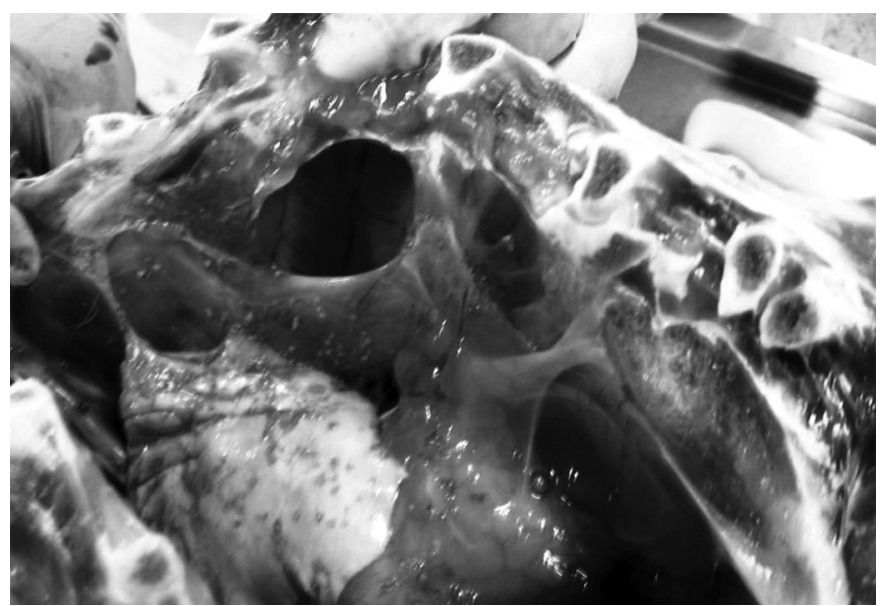

Fig.5. Pequenos nódulos granulomatosos típicos de tuberculose miliar.
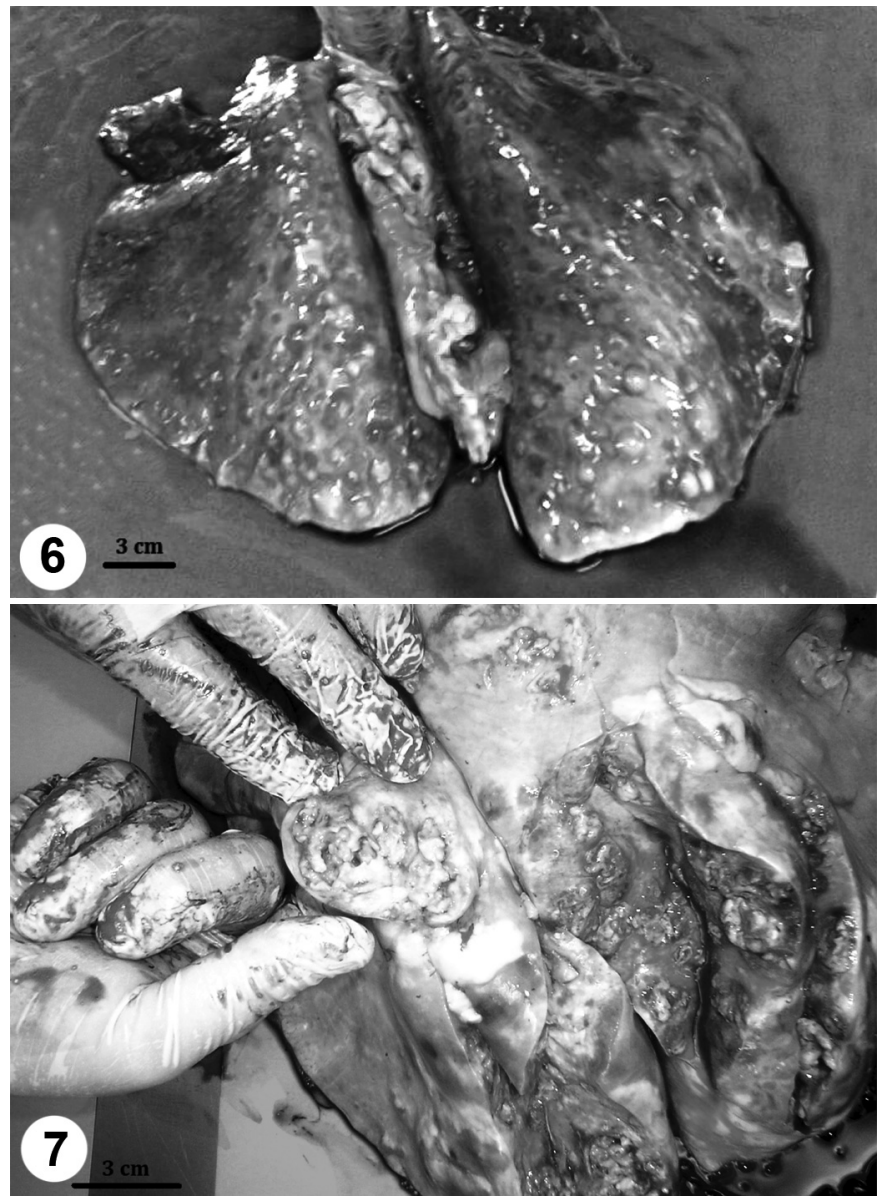

Fig.6-7. Lesões pulmonares características de tuberculose: consolidação do parênquima pulmonar, lesões nodulares salientes e difusas, granulomatosas, de tamanho variado e coloração amarelada, consistência e aspecto friável, com endurecimento num plano mais profundo, coincidindo com áreas de calcificação e de consistência arenosa ou pétrea.

formato de granulomas incompletos, caracterizadas pelo agregado concêntrico de macrófagos diferenciados em células epitelióides, que se fundiam frequentemente para formar as células gigantes de Langhans (Fig.9).

A avaliação baciloscópica de dois fragmentos pulmonares e de uma alíquota de leite, provenientes de três caprinos, demonstrou a presença de bacilos álcool-ácido resistentes (Quadro 3). 


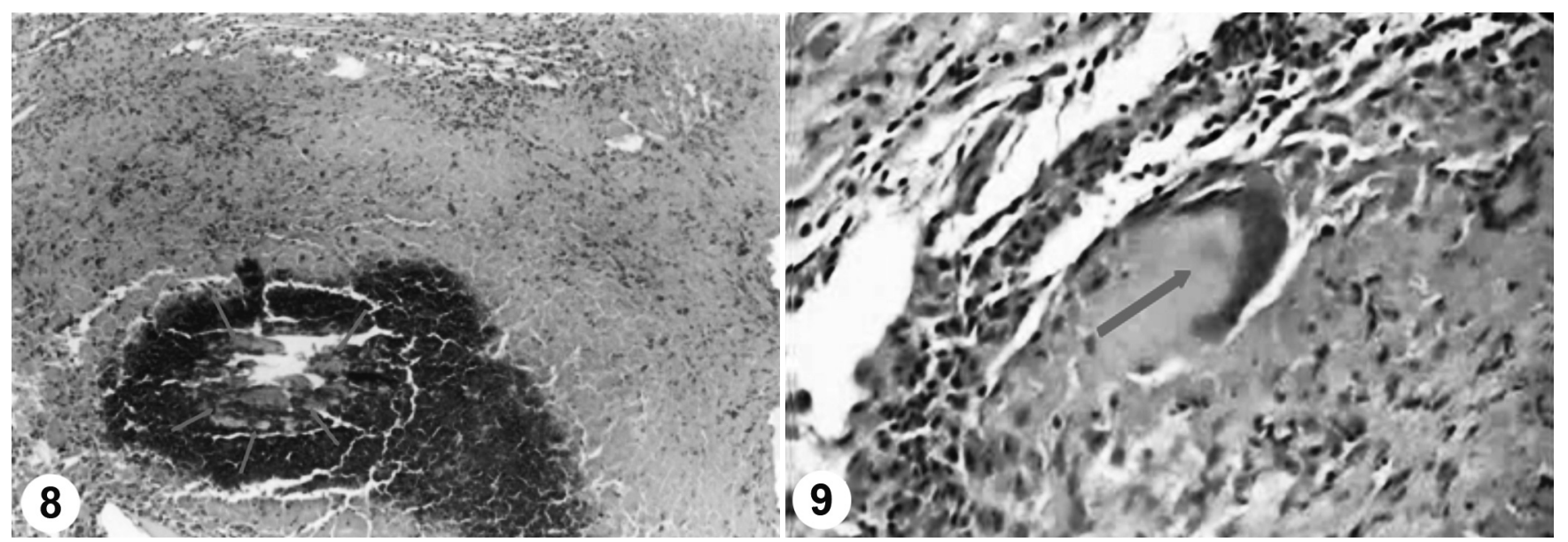

Fig.8-9. Cortes histológicos em pulmão de caprino evidenciando lesões típicas de tuberculose: necrose de caseificação, com calcificação ao centro e células gigantes de Langhans (setas). HE.

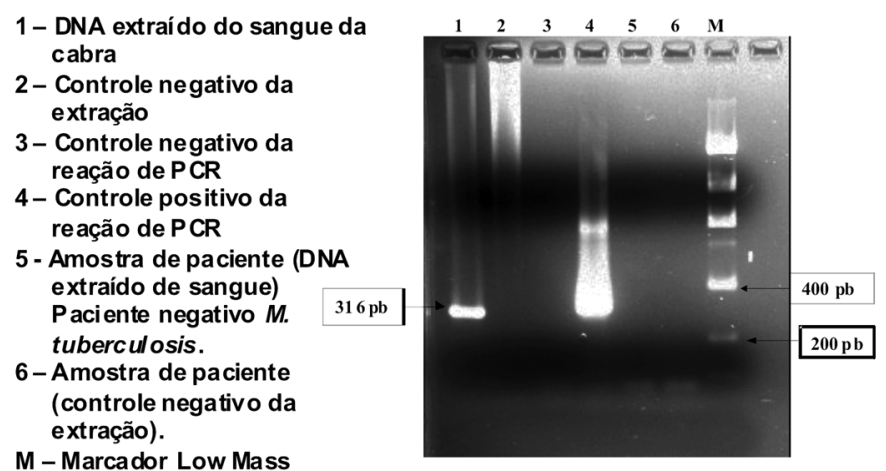

M - Marcador Low Mass Leader

AMPLIFICACุÃO

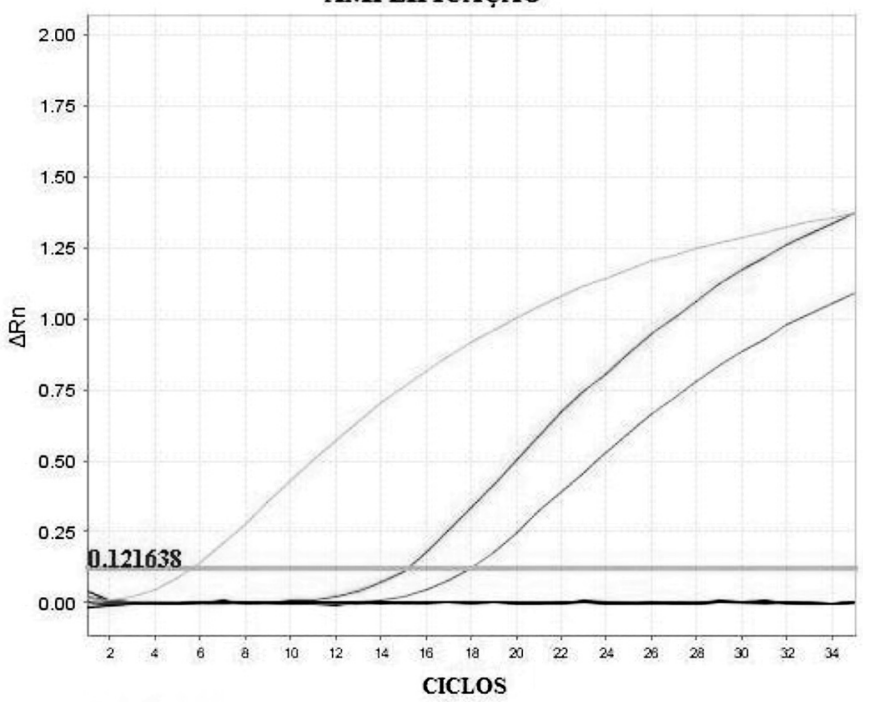

AMOSTRAS:

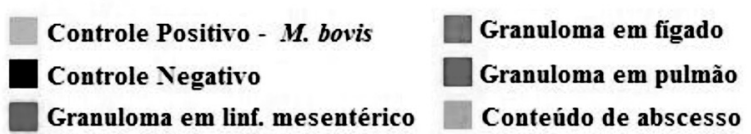

Figs.10-11. Resultado da Nested PCR: convencional (Fig.10) para o Complexo Mycobacterium tuberculosis; e em tempo real (Fig.11) para o gene MMSP6 (M. bovis), demonstrando a amplificação do controle positivo e das amostras de granuloma em linfonodo mesentérico e fígado de um caprino positivo à tuberculinização.
Amostras de DNA extraídas de sangue de uma cabra, submetidas inicialmente à PCR convencional (Fig.10), demonstraram amplificação para o gene RV2807 (Complexo M. tuberculosis). Posteriormente, amostras de DNA extraídas de linfonodo mesentérico e fígado de um caprino e fragmento de pulmão de dois outros, ao serem amplificadas pela Nested PCR em tempo real, apresentaram resultado positivo para os genes RV2807 (Complexo Mycobacterium tuberculosis) e MMSP6 (M. bovis) (Fig.11). Todas as amostras testadas resultaram negativas para o gene CD (Complexo $M$. avium). 0 uso de controles negativos conferiu segurança aos resultados.

\section{DISCUSSÃO}

Neste estudo, o teste da tuberculina, que é recomendado oficialmente no país para diagnóstico da doença em bovinos (Brasil 2006), reproduziu nos caprinos o mesmo modelo biológico classicamente observado nos bovinos, reafirmando os resultados obtidos em caprinos experimentalmente sensibilizados (Silva et al. 2006) ou naturalmente infectados (Melo et al. 2005a,b, Melo et al. 2008).

Dos sete animais retestados, dois caprinos apresentaram resultado negativo, apesar da confirmação clínica e biomolecular. Reações falso-negativas ao TCC em bovinos, anteriormente positivas, podem ocorrer em situações especiais, como em estágios avançados da tuberculose, estresse associado ao parto ou transporte, infecção intercorrente, desnutrição e exaustão física (Kleeberg 1960, Brasil 2006, Schiller et al. 2010). Nesses casos, os achados clínicos e/ ou exames complementares, como a dosagem de interferon gama, PCR e ensaio imunoenzimático, a exemplo do que se observa na espécie bovina, surgem como alternativas no auxilio ao diagnóstico da tuberculose caprina, porém, sendo necessária a padronização de tais técnicas para a espécie (Rothel et al. 1990, Collins et al. 1994, Brasil 2006, Lilenbaum \& Fonseca 2006).

Apesar o cultivo microbiológico ser indicado como teste confirmatório (Brasil 1994), o crescimento bacteriano demasiadamente lento, em consequência da reduzida quantidade de bacilos nas amostras (Corrêa \& Corrêa 1992), a utilização de meios de cultura inapropriados, o manuseio 
inadequado e a possível contaminação da mesma, são fatores que dificultam o isolamento da bactéria e podem levar a resultados falso-negativos (Roxo 1996), ratificando-se a necessidade de sua utilização associada a outros métodos diagnósticos (Medeiros et al. 2010).

Embora a identificação de Mycobacterium bovis em amostras de linfonodos mesentéricos e fígado, associada a fatores de risco para a ocorrência da tuberculose caprina, como a criação consorciada com bovinos e a difundida prática de aleitamento de cabritos com leite de vaca, de forma profilática à artrite encefalite caprina (Melo et al. 2005a), não foi possível estabelecer neste estudo que a origem da infecção nos animais tenha ocorrido pela via oral, mesmo se admitindo a transmissão pelo leite na espécie bovina (Phillips et al. 2003).

Vale ainda ressaltar que a identificação da espécie $M$. bovis, em consonância com a prévia detecção do Complexo Mycobacterium tuberculosis, evidencia a intercorrência entre a tuberculose bovina e a caprina, colocando as duas espécies ruminantes no mesmo patamar de importância como fator de risco da tuberculose zoonótica (Melo et al. 2005a).

Os resultados obtidos tornam a tuberculose caprina uma realidade no estado de Pernambuco, sendo necessárias medidas sanitárias com vistas ao controle e erradicação, devendo a baixa frequência encontrada servir de alerta para tomada de decisões e não justificar uma aparente situação de controle, tendo em vista que outros focos já foram identificados em diferentes estados (Benesi et al. 2008, Bombonato et al. 2010), após relato pioneiro no país (Melo et al. 2005b). Desta forma, estabelece-se um novo paradigma na sanidade caprina nacional, um dos mais relevantes desafios às autoridades sanitárias, produtores e comunidade científica, não apenas pelos prejuízos econômicos que a doença poderá causar, mas, também, pelas possíveis implicações na saúde pública.

Este estudo é o primeiro diagnóstico do envolvimento de $M$. bovis na tuberculose caprina no Brasil, ressaltando ainda os achados nosológicos, imunoalérgicos, radiológicos, anátomo-histopatológicos e baciloscópicos. A elucidação de sua etiopatogenia constitui o primeiro relato a descrever a entidade clínica da tuberculose caprina no país, o que contribuirá, certamente, para a implementação de ações de controle e profilaxia da tuberculose.

Agradecimentos.- Agradecemos à Universidade Federal Rural de Pernambuco pelo apoio às atividades do grupo de pesquisa, em especial ao Doutor Leonildo B.G. da Silva (Laboratório de Bacterioses do Departamento de Medicina Veterinária da UFRPE); à Doutora Haiana C. Schindler (Laboratório de Imunoepidemiologia do Centro de Pesquisas Aggeu Magalhães da UFPE); e ao Doutor Carlos A.N. Ramos (Laboratório de Sorologia da Embrapa Gado de Corte, Campo Grande/MS).

\section{REFERÊNCIAS}

Aranaz A., Cousins D., Mateos A. \& Dominiguez L. 2003. Elevation of Mycobacterium tuberculosis subsp. caprae to species rank as Mycobacterium caprae. Int. J. Syst. Evol. Microbiol. 53:1785-1789.

Araújo C.P., Osório A.L.A.R., Jorge K.S.G., Ramos C.A.N., Souza Filho A.F., Vidal C.E.S., Roxo E., Dib C.C., Rocha A., Fonseca Júnior A.A., Silva M.R. \& Araújo F.R. 2011. Diagnosis of tuberculosis using real-time PCR in cattle tissues. Anais 4⿳亠丷a Mostra Científica da Faculdade de Medicina Veterinária e Zootecnia, Campo Grande, MS. (Resumo)
Associação Brasileira de Buiatria 1998. Informativo da Associação Brasileira de Buiatria 2(12):2.

AVMA 2001. American Veterinary Medical Association guidelines on euthanasia (formerly Report of the AVMA panel on euthanasia). J. Am. Vet. Med. Assoc. 218(5):669-696.

Benesi F.., Pinheiro S.R., Maiorka P.C., Sakamoto S.M., Roxo E., Benites N.R., Birgel Junior E.H. \& Gregory L. 2008. Relato de caso: tuberculose em caprino (Capra hircus). Arqs Inst. Biológico, São Paulo, 75(2):217-220.

Bombonato N.G., Oliveira P.R. \& Lima-Ribeiro A.M.C. 2010. Aspectos epidemiológicos da tuberculose caprina na mesorregião do Triângulo Mineiro e Alto Paranaíba, MG. Arqs Inst. Biológico, São Paulo, 77(3):389384.

Brasil. 1994. Manual de Bacteriologia da Tuberculose. Ministério da Saúde. Fundação Nacional de Saúde. Coordenação Nacional de Pneumologia Sanitária, Rio de Janeiro, RJ.

Brasil 2006. Manual técnico do Programa Nacional de Controle e Erradicação da Brucelose e Tuberculose Animal. Ministério da Agricultura, Pecuária e Abastecimento, Brasília, DF.

Collins D.M., Radford A.J., De Lisle G.W. \& Billman-Jacobe H. 1994. Diagnosis and epidemiology of bovine tuberculosis using molecular biological approaches. Vet. Microbiol. 40:83-94.

Corrêa W.M. \& Corrêa C.N.M. 1992. Enfermidades infecciosas dos mamíferos domésticos. $2^{\mathrm{a}}$ ed. Medsi, Rio de Janeiro. 844p.

Cousins D.V., Bastida R., Cataldi A., Quse V., Redrobe S., Dow S., Duignan P., Murray A., Dupont C., Ahmed N., Collins D.M., Butler W.R., Dawson D., Rodríguez D., Loureiro J., Romano M.I., Alito A., Zumarraga M. \& Bernardelli A. 2003. Tuberculosis in seals caused by a novel member of the Mycobacterium tuberculosis complex: Mycobacterium pinnipedii sp. Int. J. Syst. Evol. Microbiol. 53:1305-1314.

Golden G.E. 1921. Tuberculosis in milk goats. J. Am. Vet. Med. Assoc. 59:7981.

Gutiérrez M., Samper S., Gavigan J., Garcia Marín J.F. \& Martín C. 1995. Differentiation by molecular typing of Mycobacterium bovis strains causing tuberculosis in cattle and goats. J. Clin. Microbiol. 33(11):2953-2956.

Jones T.C., Hunt R.D. \& King N.W. 1997. Veterinary pathology. $6^{\text {th }}$ ed. Lippincott Williams \& Wilkins, Baltimore. 1392p.

Kleeberg H.H. 1960. The tuberculin test in cattle. Journal of South African Veterinary Medical Association. 31:213-225.

Lilenbaum W. \& Fonseca L.S. 2006. The use of ELISA as a complementary tool for the tuberculosis eradication program in Brazil. Braz. J. Vet. Res. Anim. Sci. 43:256-261.

Marotti J., Galhardo A.P.M., Furuyama R.J., Pigozzo M.N., Campos T.N. \& Laganá D.C. 2008. Amostragem em pesquisa clínica: Tamanho da amostra. Revta Odontol. USP 20(2):186-194.

Medeiros L.S., Marassi C.D., Figueiredo E.E.S. \& Lilenbaum W. 2010. Potential application of diagnostic methods for controlling of bovine tuberculosis in Brazil. Braz. J. Microbiol. 41(3):531-541.

Melo L.E.H., Melo M.T., Almeida A.V., Saldanha S.V., Evêncio-Neto J., Tenório T.G.S., Wanderley E.K., Nascimento E.T.S., Fernandes A.C.C., Sá L.M., Barbosa D.F.A. \& Souto R.J.C. 2005a. Intercorrência entre tuberculose bovina e caprina: um fator de risco da tuberculose zoonótica no Estado de Pernambuco. Anais 1o Congresso Brasileiro de Saúde Pública Veterinária, Guarapari, ES. (Resumo)

Melo L.E.H., Melo M.T., Leite J.E.B., Maia F.C.L., Mota R.A., Schindler H.C., Lima J.F.C., Castro R.S., Santos N.V.M. \& Sá L.M. 2008. Tuberculose caprina: aspectos nosológicos, radiológicos, anátomo-histopatológicos e presença do complexo Mycobacterium tuberculosis em caprinos leiteiros do Estado de Pernambuco, Brasil. Anais 35ํㅡㄹ Conbravet, Gramado, RS. (Resumo)

Melo M.T., Melo L.E.H., Saldanha S.V., Evêncio-Neto J., Tenório T.G.S., Nascimento E.T.S. \& Fernandes A.C.C. 2005b. Ocorrência da tuberculose caprina no Estado de Pernambuco. Anais 18ª Reunião Anual do Instituto Biológico, São Paulo, SP. (Resumo)

Milne A.H. 1955. An outbreak of tuberculosis in goats in Tanganyica. Vet. Rec. 647:374-375. 
Miyazaki Y., Yoga H., Kohno S. \& Kaku M. 1993. Nested polymerase chain reaction for detection of Mycobacterium tuberculosis in clinical samples. J. Clin. Microbiol. 31:2228-2232.

Murray C., McNutt S.H. \& Purwin P. 1921. Tuberculosis of goats. J. Am. Vet. Med. Assoc. 40:82-84.

Phillips C.J.C., Foster C.R.W., Morris P.A. \& Teverson R. 2003. The transmission of Mycobacterium bovis infection to cattle. Res. Vet. Sci. 74:1-15.

Pugh D.G. 2004. Sheep and Goat Medicine. W.B. Saunders, Philadelphia. 513p.

Quinn P.J., Markey B.K., Carter M.E., Donnelly W.J. \& Leonard E.C. 2005. Microbiologia Veterinária e Doenças Infecciosas. Artmed, Porto Alegre. 512p.

Radostits O.M., Gay C.C., Hinchcliff K.W. \& Constable P.D. 2007. Veterinary Medicine: A textbook of the diseases of cattle, horses, sheep, pigs, and goats. $10^{\text {th }}$ ed. W.B. Saunders, Philadelphia. $1770 \mathrm{p}$.

Reynoso B.A., Casilas I.C.R., Aparicio E.D., Elizando G.V. \& Flores M.A.S. 1999. Diagnostico de tuberculosis en hatos de caprinos empleando la prueba intradermica doble comparativa y cultivo bacteriológico. Tecnica Pecuaria en Mexico 37:55-58.

Rothel J.S., Jones S.L., Corner L.A., Cox J.C. \& Wood P.R. 1990. A sandwich enzyme immunoassay for bovine interferon-gamma and its use for the detection of tuberculosis in cattle. Aust. Vet. J. 67:134-137.

Roxo E. 1996. Tuberculose bovina: revisão. Arqs. Inst. Biológico, São Paulo, 63(2):91-97.

Schiller I., Oesch B., Vordermeier H.M., Palmer M.V., Harris B.N., Orloski K.A., Buddle B.M., Thacker T.C., Lyashchenko K.P. \& Waters W.R. 2010. Bovine tuberculosis: A review of current and emerging diagnostic techniques in view of their relevance for disease control and eradication. Transbound. Emerg. Dis. 57:205-220.

Silva P.E.G., Pinheiro S.R., Leal M.L.R., Bertagnon H.G., Mota P., Sinhorino I.L., Vasconcellos S.A. \& Benesi F.J. 2006. Teste de tuberculinização em caprinos (Capra hircus) experimentalmente sensibilizados. Ciência Rural 36(3):880-886. 